\title{
NiMoCo layered double hydroxides for electrocatalyst and supercapacitor electrode
}

\author{
Hengqi Liu ${ }^{1}$, Depeng Zhao ${ }^{1}$, Ying Liu ${ }^{1}$, Yongli Tong ${ }^{1}$, Xiang $\mathrm{Wu}^{{ }^{*}}$ and Guozhen Shen ${ }^{2^{*}}$
}

\begin{abstract}
Non-noble-metal electrode materials with high durability and efficiency have become the frontiers of energy conversion and storage fields. However, conventional electrode materials often show high overpotential and low conductivity. To solve this problem, we fabricate a $\mathrm{NiMo}_{x} \mathrm{Co}_{2-x}$ layered double hydroxide (LDH)/Ni foam (NF) product through a facile hydrothermal route. The as-prepared NiMoCo-LDH/NF catalyst possesses an overpotential of $123 \mathrm{mV}$ for hydrogen evolution reaction (HER) at $10 \mathrm{~mA} \mathrm{~cm}^{-2}$ and $279 \mathrm{mV}$ for oxygen evolution reaction (OER) at $20 \mathrm{~mA} \mathrm{~cm}$. The as-obtained product exhibits excellent overall water splitting performances. Meanwhile, as the electrode material for supercapacitor, it delivers high specific capacitance and excellent cyclic performance. The asymmetric supercapacitor assembled with NiMoCo-LDH/NF//active carbon exhibits $93 \%$ of its initial capacity after 8000 cycles.
\end{abstract}

Keywords: layered double hydroxide, hydrogen evolution reaction, oxygen evolution reaction, overall water splitting, supercapacitor, energy density

\section{INTRODUCTION}

With the rapid development of human society, the demands for energy resources have become very imperious [1-3]. Currently, most of energy comes from traditional fossil fuels [4-6]. However, they might cause serious environmental pollution, and thus it is urgent to seek for alternative clean energy sources to solve the problem. Hydrogen is widely used owing to its unique superiority such as zero carbon emission, abundant reservation and high efficiency [7-9]. Electrochemical water splitting has been identified as one of the most prosperous hydrogen production technologies $[10,11]$. However, their two reactions exhibit sluggish kinetic processes and high overpotentials [12-14]. It is still a challenge for rational design of catalysts to accelerate their half reaction rates. Gen- erally speaking, noble metal-based catalysts show fast reaction kinetics. Nevertheless, high cost and scarcity limit their widespread applications [15-17].

Recently, many transition metal hydroxides have been widely investigated as electrochemical catalysts $[18,19]$. Among them, layered double hydroxides (LDHs) stand out due to their adjustable composition, low cost and high activity [20-22]. Thus far, several high-performance LDH structures have been reported, such as NiFe-LDH arrays, NiCo-LDH and ZnCo-LDH electrocatalysts [2325]. However, for overall water splitting, they behave with low specific surface area and poor conductivity. These problems can be effectively solved by the reasonable selection and design of electrode materials. For example, Yao et al. [26] synthesized $\mathrm{Ni} / \mathrm{Co} / \mathrm{Fe}$ phosphosulfide nanorods through a hydrothermal electrodeposition route. The as-obtained products possess an overpotential of $195 \mathrm{mV}$ (oxygen evolution reaction, OER) and $97.8 \mathrm{mV}$ (hydrogen evolution reaction, HER) at a current density of $10 \mathrm{~mA} \mathrm{~cm}^{-2}$. Chanda and coworkers [27] fabricated a Li-doped NiFeCo oxide catalyst with an overpotential of $220 \mathrm{mV}$ at $10 \mathrm{~mA} \mathrm{~cm}{ }^{-2}$ for OER. In addition, Xie et al. [28] studied the importance of coexistence of ion pairs. They thought that the specific sites of oxygen adsorption $\left(\mathrm{Co}^{2+}-\mathrm{O}-\mathrm{Co}^{3+}\right)$ can improve the catalyst's activity. Inspired from excellent redox activity of molybdenum under mild reaction, nickel, another active transition metal, usually combines with other materials [29]. Fan's group [30] reported that addition of $\mathrm{Ni}$ ion into $\mathrm{CeO}_{2}$ can improve its catalytic performance due to the enhanced redox activity and oxygen storage capacity.

In addition, supercapacitors have attracted extensive attention because they possess excellent cycling stability and fast charge/discharge ability [31-33]. However, the capacitors based on traditional metal oxides still suffer from low energy density, which limits their practical ap-

${ }^{1}$ School of Materials Science and Engineering, Shenyang University of Technology, Shenyang 110870, China

${ }^{2}$ State Key Laboratory for Superlattices and Microstructures, Institute of Semiconductors, Chinese Academy of Sciences, Beijing 100083, China

*Corresponding authors (emails: wuxiang05@sut.edu.cn (Wu X); gzshen@semi.ac.cn (Shen G)) 
plications [34]. Therefore, the design of novel electrodes has become a big challenge. Thereinto, $\mathrm{LDH}$ can improve the entire electrode surface and promote the ion adsorption from the electrolyte to increase the energy density. For example, Qiu's group [35] fabricated NiCoAl-LDH nanoplates with an energy density of $14.9 \mathrm{~W} \mathrm{~h} \mathrm{~kg}^{-1}$ at $51.5 \mathrm{~kW} \mathrm{~kg}^{-1}$. Zhou et al. [36] reported $\mathrm{Co}_{3} \mathrm{O}_{4} @ \mathrm{CoNi}-\mathrm{LDH}$ core/shell nanosheet arrays exhibiting a high energy density $\left(61.23 \mathrm{~W} \mathrm{~h} \mathrm{~kg}^{-1}\right)$ at a power density of $750 \mathrm{~W} \mathrm{~kg}^{-1}$.

In this work, we prepare a series of $\mathrm{NiMo}_{x} \mathrm{Co}_{2-x}-\mathrm{LDH} /$ $\mathrm{Ni}$ foam (NF) catalysts directly grown on NF by a facile hydrothermal route. The NiMoCo-LDH/NF electrode exhibits an overpotential of $123 \mathrm{mV}$ at $10 \mathrm{~mA} \mathrm{~cm}^{-2}$ for HER and excellent OER performance. When used as the electrocatalyst for overall water splitting, it shows a cell voltage of $1.71 \mathrm{~V}$ at a current density of $20 \mathrm{~mA} \mathrm{~cm}^{-2}$ and stability for more than $14 \mathrm{~h}$. Meanwhile, as the capacitor electrode material, it delivers high specific capacitance and excellent cyclic performance. The asymmetric supercapacitor (ASC) assembled with NiMoCo-LDH/NF//active carbon $(\mathrm{AC})$ exhibits a high energy density at a power density of $2695 \mathrm{~W} \mathrm{~kg}^{-1}$ and $93 \%$ of its capacitance retention after 8000 cycles.

\section{EXPERIMENTAL SECTION}

$\mathrm{Ni}\left(\mathrm{NO}_{3}\right)_{2} \cdot 6 \mathrm{H}_{2} \mathrm{O}, \mathrm{Co}\left(\mathrm{NO}_{3}\right)_{2} \cdot 6 \mathrm{H}_{2} \mathrm{O}$ and $\mathrm{Na}_{2} \mathrm{MoO}_{4} \cdot 6 \mathrm{H}_{2} \mathrm{O}$ were obtained from Shanghai Aladdin Bio-Chem Technology Co. Ltd. Urea and $\mathrm{NH}_{4} \mathrm{~F}$ were purchased from Sigma-Aldrich. All chemical reagents were used as purchased. Before the experiment, a piece of NF $(3 \mathrm{~cm} \times 3 \mathrm{~cm})$ was immersed into $0.5 \mathrm{~mol} \mathrm{~L}^{-1} \mathrm{HCl}$ solution. Next, it was washed with ethanol and deionized water under sonication successively, and then dried overnight.

$\mathrm{NiMo}_{x} \mathrm{Co}_{2-x}-\mathrm{LDH} / \mathrm{NF}$ nanosheets were prepared by a facile hydrothermal method. $\mathrm{Ni}\left(\mathrm{NO}_{3}\right)_{2} \cdot 6 \mathrm{H}_{2} \mathrm{O}, \mathrm{Co}\left(\mathrm{NO}_{3}\right)_{2}$. $6 \mathrm{H}_{2} \mathrm{O}$ and $\mathrm{Na}_{2} \mathrm{MoO}_{4} \cdot 6 \mathrm{H}_{2} \mathrm{O}$ with a molar ratio of $2: x:(2-x)$ were dissolved in $50 \mathrm{~mL}$ deionized water. Afterwards, $5 \mathrm{mmol}$ urea and equal quantity of $\mathrm{NH}_{4} \mathrm{~F}$ were added to the above solution under constant stirring. Then a piece of pre-treated NF with the above mixture was transferred into an autoclave and heated at $140^{\circ} \mathrm{C}$ for $6 \mathrm{~h}$. After being cooled to room temperature, the as-synthesized samples were cleaned with deionized water and dried at $60^{\circ} \mathrm{C}$. The loading amounts of $\mathrm{NiMo}_{2}-\mathrm{LDH}, \mathrm{NiMo}_{1.5} \mathrm{Co}_{0.5}-\mathrm{LDH}$, NiMoCo-LDH, $\mathrm{NiMo}_{0.5} \mathrm{Co}_{1.5}-\mathrm{LDH}$ and $\mathrm{NiCo}_{2}-\mathrm{LDH}$ materials on a substrate of $1.0 \mathrm{~cm}^{2}$ were about $2.1,1.9,1.7$, 1.6 , and $2.0 \mathrm{mg}$, respectively.

X-ray diffraction analyzer (XRD, Shimadzu-7000) with a $\mathrm{Cu} \mathrm{Ka}$ radiation $(\lambda=0.1541 \mathrm{~nm}, 40 \mathrm{kV})$ and $\mathrm{X}$-ray photoelectron spectra (XPS, ESCALAB250) with an Al Ka source were used to investigate the phase composition and crystal structure of the samples. The structure and morphology of the products were characterized by using a scanning electron microscope (SEM, Gemini, 300-71-31).

Electrocatalytic performances of the samples were investigated by using a CHI660E electrochemical workstation in a standard three-electrode system. The samples were used as the working electrode. $\mathrm{An} \mathrm{Ag} / \mathrm{AgCl}$ electrode with saturated $\mathrm{KCl}$ solution was used as the reference electrode through a double salt-bridge and luggin capillary. And it was calibrated before and after the experiments to ensure accuracy. The $\mathrm{Ag} / \mathrm{AgCl}$ reference electrode was not directly contacted to the alkaline electrolyte but via the salt-bridge full of saturated $\mathrm{KCl}$ solution that can eliminate the diffusion potential and maintain its stability. Without this salt-bridge, the accuracy of the $\mathrm{Ag} / \mathrm{AgCl}$ reference electrode will be reduced because of its corrosion in the alkaline electrolyte. Pt foil was used as the counter electrode for OER (graphite counter electrode for HER) in $1 \mathrm{~mol} \mathrm{~L}^{-1} \mathrm{KOH}$ (pH 13.7) electrolyte. All potentials were calculated by using the follow equation:

$E_{\mathrm{RHE}}=E_{\mathrm{Ag} / \mathrm{AgCl}}+0.197 \mathrm{~V}+0.059 \mathrm{~V} \times \mathrm{pH}$,

where $E_{\mathrm{RHE}}$ is the potential of the reversible hydrogen electrode (RHE), $E_{\mathrm{Ag} / \mathrm{AgCl}}$ represents the experimentally measured potential against the $\mathrm{Ag} / \mathrm{AgCl}$ reference electrode. All overpotentials $(\eta)$ of OER were studied through the equation:

$\eta=E_{\mathrm{RHE}}-1.23$.

Linear sweep voltammetry (LSV) polarization curves were measured from 0 to $0.7 \mathrm{~V}$ (OER), from -1.45 to $-0.9 \mathrm{~V}$ (HER) and between 0 and $2.0 \mathrm{~V}$ (overall water splitting). Electrochemical impedance spectra (EIS) were evaluated at the open-circuit potential in the frequency range of 10 to $100 \mathrm{mHz}$. The electrochemical active surface area (ECSA) was analyzed by cyclic voltammetry (CV) curves at various scan rates.

$\mathrm{CV}$ measurements, galvanostatic charge-discharge (GCD) curves, and EIS measurements were investigated in a standard three-electrode system in $3 \mathrm{~mol} \mathrm{~L}^{-1} \mathrm{KOH}$ electrolytes. The as-prepared samples were used as the working electrode, $\mathrm{Pt}$ foil as the counter electrode and $\mathrm{Hg} / \mathrm{HgO}$ as the reference.

An ASC was constructed by using the NiMoCo-LDH/ $\mathrm{NF}$ sample as the cathode and AC as the anode. The energy density $(E)$ and power density $(P)$ of the ASC can be calculated by the equations below: 
$E=1 / 2 C V^{2}$,

$P=3600 E / t$,

where $E\left(\mathrm{~W} \mathrm{~h} \mathrm{~kg}^{-1}\right)$ is the energy density, $P\left(\mathrm{~W} \mathrm{~kg}^{-1}\right)$ is the power density, $C\left(\mathrm{~F} \mathrm{~g}^{-1}\right)$ is the specific capacitance, $V(\mathrm{~V})$ is voltage range, $t(\mathrm{~s})$ is the total discharge time.

\section{RESULTS AND DISCUSSION}

The crystal structures of the as-obtained samples were firstly investigated by XRD. The peaks marked with "*” are from NF (Fig. 1a, b). The diffraction patterns of $\mathrm{NiMo}_{x} \mathrm{Co}_{2-x}-\mathrm{LDH}(x=2)$ can be indexed to standard cubic spinal $\mathrm{NiMoO}_{4} \cdot x \mathrm{H}_{2} \mathrm{O}$ phase (JCPDF No. 13-0128) $\left(\mathrm{NiMo}_{2}-\mathrm{LDH}\right)$. When the molar ratio of $\mathrm{Ni}, \mathrm{Mo}$ and $\mathrm{Co}$ elements is 1:0:2, the crystal structure changes into $(\mathrm{Co}, \mathrm{Ni}) \mathrm{O}(\mathrm{OH})$ phases (JCPDF No. 29-0491), named as $\mathrm{NiCo}_{2}$-LDH. In Fig. 1b, with increasing Co content, the characteristic peaks gradually shift to $\mathrm{NiCo}_{2}-\mathrm{LDH}$ phases.

Surface chemical states and elemental composition of the as-prepared NiMoCo-LDH electrode were analyzed by XPS. In Fig. 1c, the XPS spectrum of Ni $2 p$ consists of four peaks, which include two spin-orbit doublets of $\mathrm{Ni} 2 \mathrm{p}_{3 / 2}$ and $\mathrm{Ni} 2 \mathrm{p}_{1 / 2}$ and two shakeup satellites. Two main peaks at 854.5 and $873.1 \mathrm{eV}$ with spin-orbit splitting of $18.6 \mathrm{eV}$ correspond to $\mathrm{Ni} 2 \mathrm{p}_{3 / 2}$ and $\mathrm{Ni} 2 \mathrm{p}_{1 / 2}$. The ones at 854.5 and $873.1 \mathrm{eV}$ can be attributed to $\mathrm{Ni}^{3+}$, and the fitted peaks centered at 853.1 and $871.2 \mathrm{eV}$ correspond to
$\mathrm{Ni}^{2+}$ [37,38]. Additionally, the peaks at 860.6 and $879.3 \mathrm{eV}$ can be ascribed to charge-transfer shakeup satellite peaks. From XPS spectra of Co 2 p (Fig. 1d), two strong peaks at 778.9 and $795.1 \mathrm{eV}$ correspond to Co $2 \mathrm{p}_{3 / 2}$ and Co $2 p_{1 / 2}$. The peaks at binding energies of 771.2 and $795.1 \mathrm{eV}$ could be indexed to $\mathrm{Co}^{3+}$, and the one at $799.1 \mathrm{eV}$ is ascribed to $\mathrm{Co}^{2+}$. Meanwhile, two shakeup satellite peaks are also observed at 783.9 and $801.6 \mathrm{eV}$ $[39,40]$. Fig. 1e exhibits the Mo $3 \mathrm{~d}$ spectra. The binding energies of 229.3 and $232.5 \mathrm{eV}$ correspond to Mo $3 \mathrm{~d}_{5 / 2}$ and Mo $3 d_{3 / 2}$, respectively [41]. O 1s spectra (Fig. 1f) are composed of three main peaks (denoted as $\mathrm{O} 1, \mathrm{O} 2$ and $\mathrm{O} 3$ ), where $\mathrm{O} 1$ is metal oxygen bonds, $\mathrm{O} 2$ represents oxygen ions and $\mathrm{O} 3$ denotes the physicochemically adsorbed water at the surface of active material [42].

Then the morphologies of the as-prepared samples were observed by SEM. In Fig. 2a and b, the $\mathrm{NiMo}_{2}-\mathrm{LDH}$ electrode presents flower-like shapes and consists of the interconnected nanosheets. The average thickness of the nanosheets is around $20 \mathrm{~nm}$. SEM images of the $\mathrm{NiCo}_{2}-$ LDH material also exhibit the morphology of nanosheets, which are closely covered on the surface of NF (Fig. 2d, e). Fig. $2 c$ and $f$ show the corresponding element mappings. Energy-dispersive X-ray spectroscopy (EDS) mappings of $\mathrm{NiMo}_{x} \mathrm{Co}_{2-x}$ - $\mathrm{LDH}$ samples demonstrate that elements of $\mathrm{Ni}, \mathrm{Mo}$, Co and $\mathrm{O}$ are uniformly distributed on the sample surfaces.
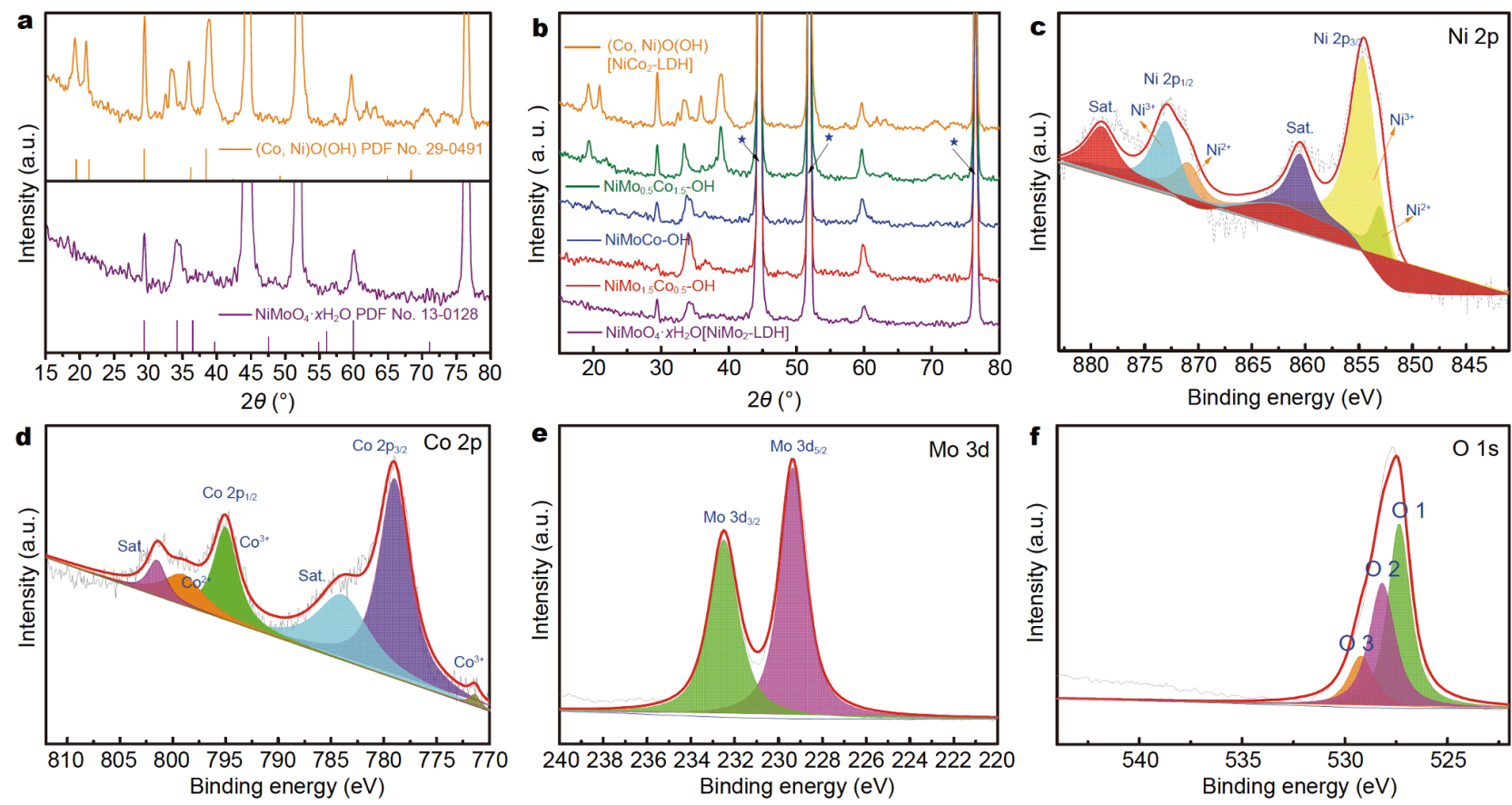

Figure 1 (a, b) XRD patterns of the as-prepared samples. XPS spectra of the NiMoCo-LDH sample: (c) Ni 2p, (d) Co 2p, (e) Mo 3d, (f) O 1s. 

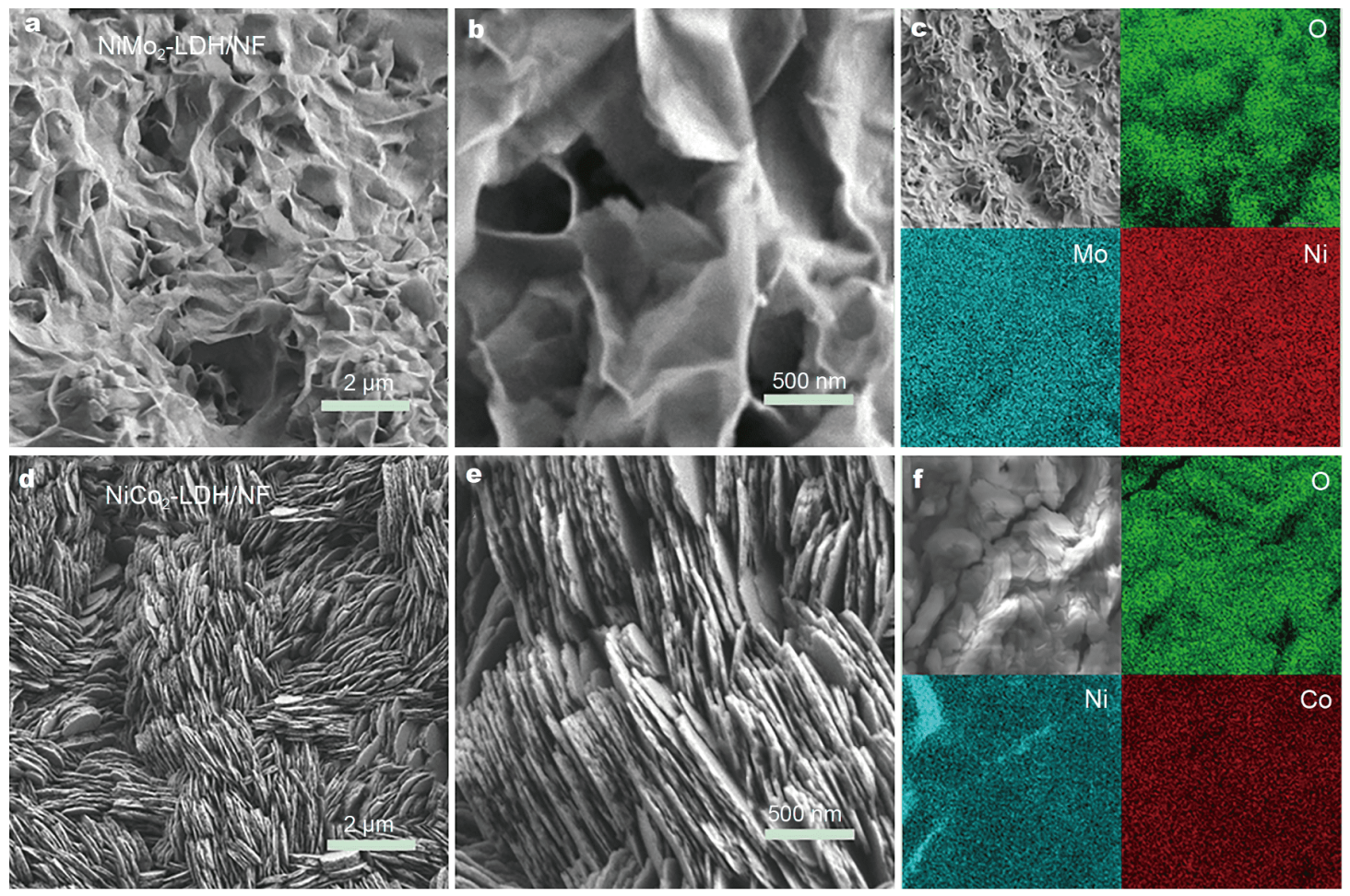

Figure 2 Low- and high-magnification SEM images, and elemental mappings of the $\mathrm{NiMo}_{2}-\mathrm{LDH}$ samples (a-c), and the $\mathrm{NiCo}_{2}-\mathrm{LDH}^{2}$ electrodes (d-f).

Besides, morphology variation of the samples coated on NF was investigated. It is found that the spaces between nanosheets gradually increase and eventually generate individual nanosheets with the content of Mo decreasing (Fig. 3a-c). When the atomic percentage of Mo element is 4.98 , the distance between the individual nanosheets is about $500 \mathrm{~nm}$, and they are staggered and vertically grown on the substrate instead of being stacked layer by layer, resulting in full contact of the electrolyte for enhanced available active sites. The nanosheets of the samples are stacked on top of each other when only two elements are present in the materials (Mo 0 at\%). The corresponding high-magnification SEM images are shown in Fig. 3d-f.

To study the electrocatalytic performances of the asprepared samples, HER experiments were conducted in a standard three-electrode system in $1.0 \mathrm{~mol} \mathrm{~L}^{-1} \mathrm{KOH}$ at a scan rate of $5 \mathrm{mV} \mathrm{s}^{-1}$. As shown in Fig. 4a, NiMoCo$\mathrm{LDH} / \mathrm{NF}\left(\eta\right.$ at $\left.10 \mathrm{~mA} \mathrm{~cm}{ }^{-2}, \eta_{10}=123 \mathrm{mV}\right)$ is superior to $\mathrm{NiMo}_{2}-\mathrm{LDH} / \mathrm{NF}\left(\eta_{10}=167 \mathrm{mV}\right), \mathrm{NiMo}_{1.5} \mathrm{Co}_{0.5} \mathrm{LDH} / \mathrm{NF}$ $\left(\eta_{10}=149 \mathrm{mV}\right), \mathrm{NiMo}_{0.5} \mathrm{Co}_{1.5}-\mathrm{LDH} / \mathrm{NF}\left(\eta_{10}=169 \mathrm{mV}\right)$ and $\mathrm{NiCo}_{2}-\mathrm{LDH} / \mathrm{NF}\left(\eta_{10}=178 \mathrm{mV}\right)$ electrodes. To evaluate HER kinetics of the electrodes, Tafel slopes (Fig. 4b) were calculated on the basis of LSV curves. The liner part of Tafel plot was obtained by the following equation [43]: $\eta=a+b \log j . \eta$ represents the overpotential, $b$ is the Tafel slope and $j$ denotes the current density. The Tafel slopes of $\mathrm{NiMo}_{2}-\mathrm{LDH} / \mathrm{NF}, \mathrm{NiMo}_{1.5} \mathrm{Co}_{0.5}-\mathrm{LDH} / \mathrm{NF}, \mathrm{NiMoCo}-$ $\mathrm{LDH} / \mathrm{NF}, \quad \mathrm{NiMo}_{0.5} \mathrm{Co}_{1.5}-\mathrm{LDH} / \mathrm{NF}$ and $\mathrm{NiCo}_{2}-\mathrm{LDH} / \mathrm{NF}$ electrodes are 191.64, 101.55, 67.39, 157.48 and $159.20 \mathrm{mV} \mathrm{dec}^{-1}$, respectively. The low slope of NiMoCo$\mathrm{LDH} / \mathrm{NF}$ catalyst further shows favorable kinetics for HER. From Fig. 4c, the NiMoCo-LDH/NF sample possesses the smallest overpotential.

ECSA was then examined by the electrochemical double layer capacitance $\left(C_{\mathrm{dl}}\right)$. Large $C_{\mathrm{dl}}$ value reveals that electrocatalysts possess plentiful exposed active catalytic sites, which facilitates the adsorption of water molecules [44]. As shown in Fig. $4 \mathrm{~d}, C_{\mathrm{dl}}$ of NiMoCo-LDH/NF $\left(7.45 \mathrm{mF} \mathrm{cm}{ }^{-2}\right.$ ) electrode is higher than those of $\mathrm{NiMo}_{2}$ $\mathrm{LDH} / \mathrm{NF} \quad\left(3.87 \mathrm{mF} \quad \mathrm{cm}^{-2}\right), \quad \mathrm{NiMo}_{1.5} \mathrm{Co}_{0.5}-\mathrm{LDH} / \mathrm{NF}$ $\left(5.11 \mathrm{mF} \mathrm{cm}{ }^{-2}\right), \mathrm{NiMo}_{0.5} \mathrm{Co}_{1.5}-\mathrm{LDH} / \mathrm{NF}\left(4.93 \mathrm{mF} \mathrm{cm}^{-2}\right)$, and $\mathrm{NiCo}_{2}-\mathrm{LDH} / \mathrm{NF}\left(3.11 \mathrm{mF} \mathrm{cm}{ }^{-2}\right)$.

EIS reflects the kinetics of the electrode/electrolyte surface. In Fig. 4e, the NiMoCo-LDH/NF possesses larger slope than other electrodes, revealing the rapid electron transfer ability. Meanwhile, the solution resistance $\left(R_{\mathrm{s}}\right)$ values of $\mathrm{NiMo}_{2}-\mathrm{LDH} / \mathrm{NF}, \mathrm{NiMo}_{1.5} \mathrm{Co}_{0.5}-\mathrm{LDH} / \mathrm{NF}, \mathrm{Ni}-$ MoCo-LDH/NF, $\mathrm{NiMo}_{0.5} \mathrm{Co}_{1.5} \mathrm{LDH} / \mathrm{NF}$ and $\mathrm{NiCo}_{2}-$ $\mathrm{LDH} / \mathrm{NF}$ electrodes are 2.14, 2.21, 2.02, 2.32 and $2.59 \Omega$, 

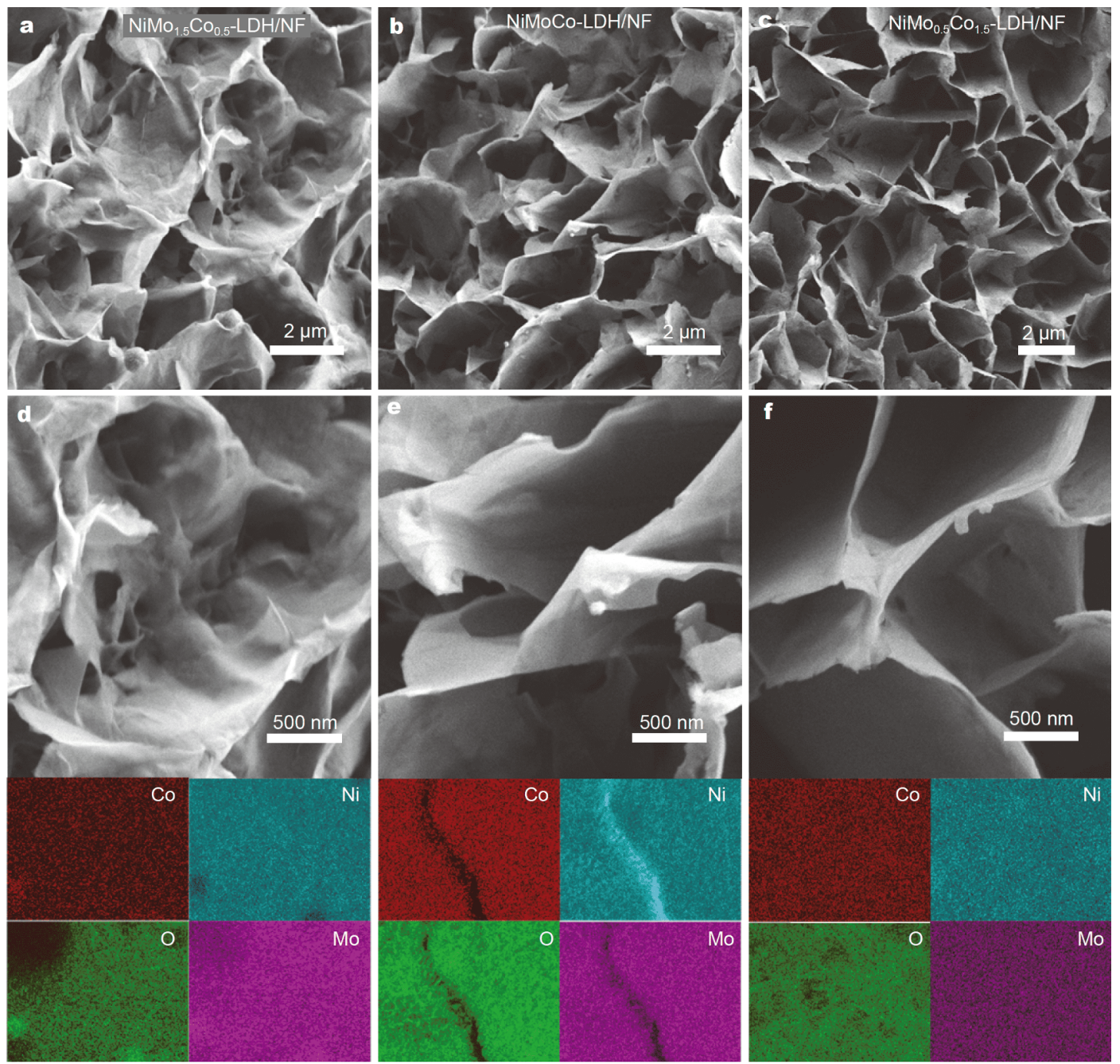

Figure $3(\mathrm{a}-\mathrm{c})$ Low-magnification SEM images of $\mathrm{NiMo}_{x} \mathrm{Co}_{2-x}-\mathrm{LDH} / \mathrm{NF}$; $(\mathrm{d}-\mathrm{f})$ the corresponding high-magnification SEM images and elemental mappings.

respectively. Cycle performance is another critical parameter for an electrocatalyst. As shown in Fig. 4f, the NiMoCo-LDH/NF electrocatalyst still maintains excellent catalytic stability even after $14 \mathrm{~h}$.

OER performances of the electrode materials were investigated at a scan rate of $2 \mathrm{mV} \mathrm{s}^{-1}$ in $1.0 \mathrm{~mol} \mathrm{~L}^{-1} \mathrm{KOH}$ electrolyte. From the LSV curves shown in Fig. 5a, the NiMoCo-LDH/NF catalyst exhibits an overpotential of $279 \mathrm{mV}$ at a current density of $20 \mathrm{~mA} \mathrm{~cm}$, which is significantly smaller than those of $\mathrm{NiMo}_{2}-\mathrm{LDH} / \mathrm{NF}$ (386 mV), $\mathrm{NiMo}_{1.5} \mathrm{Co}_{0.5} \mathrm{LDH} / \mathrm{NF}(305 \mathrm{mV}), \mathrm{NiMo}_{0.5} \mathrm{Co}_{1.5^{-}}$ $\mathrm{LDH} / \mathrm{NF}(306 \mathrm{mV})$ and $\mathrm{NiCo}_{2}-\mathrm{LDH} / \mathrm{NF}(359 \mathrm{mV})$ electrodes, respectively. Obviously, bimetallic $\mathrm{NiMo}_{2}-\mathrm{LDH} /$ $\mathrm{NF}$ and $\mathrm{NiCo}_{2}-\mathrm{LDH} / \mathrm{NF}$ show poor OER activity than other ternary electrode materials.

Further evaluation of OER activity was conducted from the Tafel slopes (Fig. 5b). The Tafel slope of $77.99 \mathrm{mV} \mathrm{dec}^{-1}$ for NiMoCo-LDH/NF sample is much lower than $107.29 \mathrm{mV} \mathrm{dec}^{-1}$ for $\mathrm{NiMo}_{2}-\mathrm{LDH} / \mathrm{NF}, 99.53$ $\mathrm{mV} \mathrm{dec}{ }^{-1}$ for $\mathrm{NiMo}_{1.5} \mathrm{Co}_{0.5}-\mathrm{LDH} / \mathrm{NF}, 101.63 \mathrm{mV} \mathrm{dec}{ }^{-1}$ for $\mathrm{NiMo}_{0.5} \mathrm{Co}_{1.5}-\mathrm{LDH} / \mathrm{NF}$ and $94.85 \mathrm{mV} \mathrm{dec}{ }^{-1}$ for $\mathrm{NiCo}_{2}{ }^{-}$ $\mathrm{LDH} / \mathrm{NF}$ electrodes. As shown in Fig. $5 \mathrm{c}$, the $C_{\mathrm{dl}}$ of $12.8 \mathrm{mF} \mathrm{cm}^{-2}$ for NiMoCo-LDH/NF catalyst is higher than those of other electrodes, revealing that increasing the exposed active sites can enhance the electrochemical performance of the electrodes. EIS spectra are shown in Fig. 5d. In the low frequency region, the slope of NiMoCo-LDH/NF is larger than those of other electrodes, indicating its low ion diffusion resistance. To further investigate the diffusion speed of ions in the electrolyte, the diffusion speed was analyzed by the following equation: 

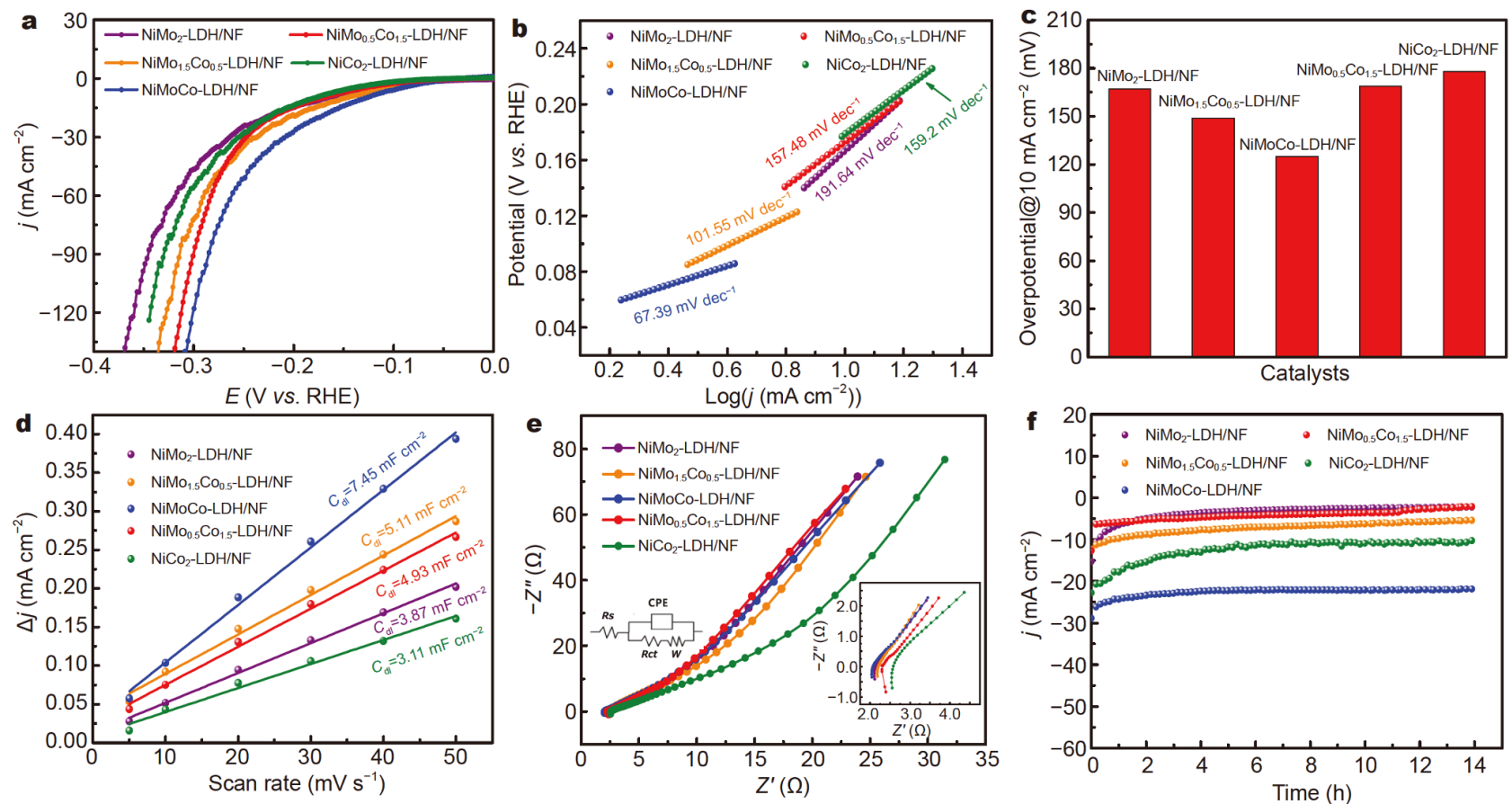

Figure 4 HER performances of the electrode samples: (a) LSV curves, (b) Tafel plots, (c) overpotential, (d) double-layered capacitance linear fitting, (e) Nyquist plots, (f) chronoamperometric stability tests.
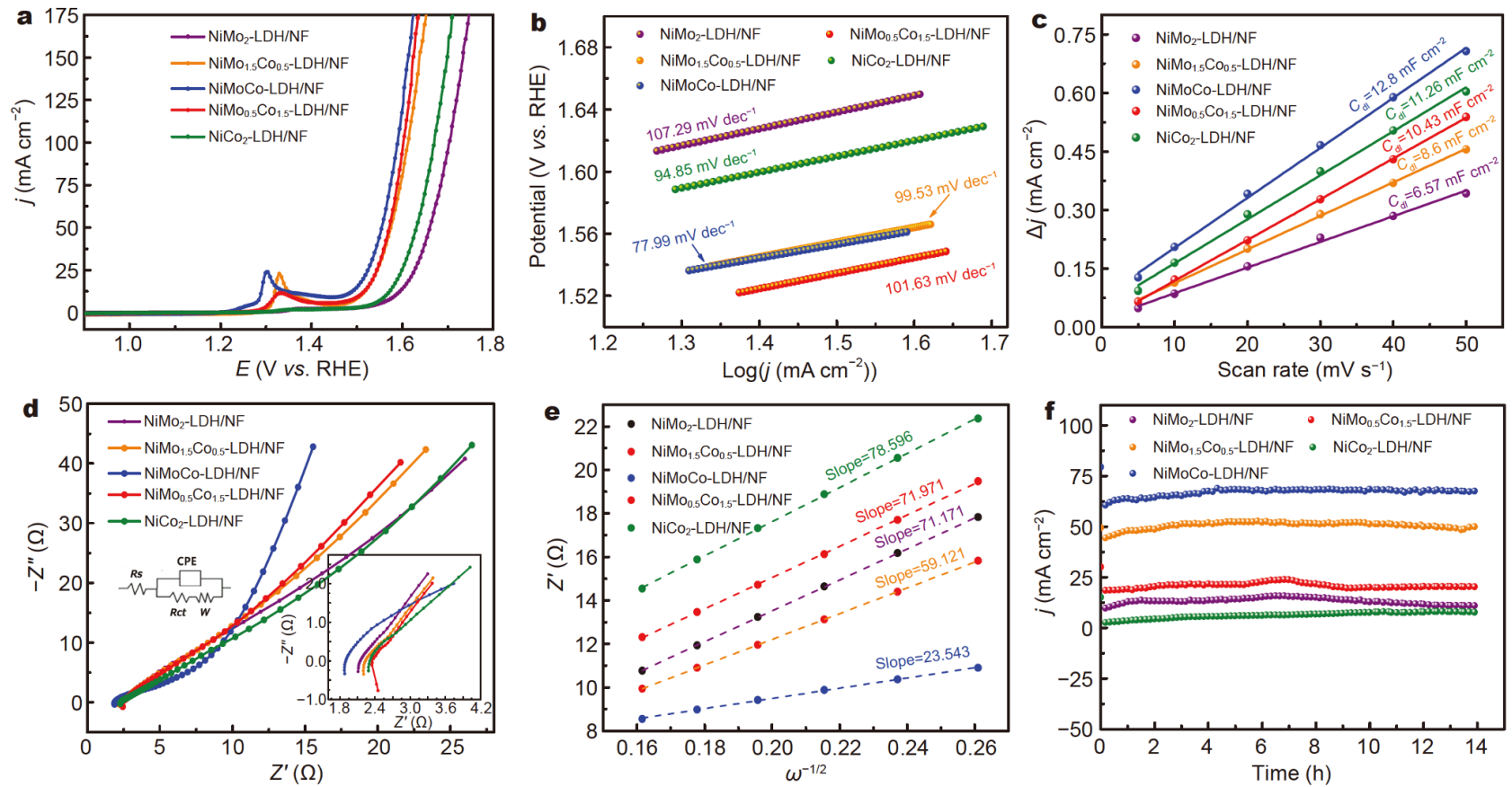

Figure 5 OER performances of the materials: (a) LSV curves, (b) Tafel plots, (c) double-layered capacitance linear fitting, (d) Nyquist plots, (e) $Z^{\prime}$ as a function of $\omega^{-1 / 2}$ plot at the low frequency region, (f) chronoamperometric stability tests. 


$$
Z=R_{\mathrm{s}}+R_{\mathrm{ct}}+\sigma_{\mathrm{w}} \omega^{-1 / 2}
$$

where $\sigma_{\mathrm{w}}$ is the Warburg factor, $\omega$ represents the angular frequency, $R_{\mathrm{ct}}$ represents the charge transfer resistance, and $Z$ denotes the diffusive resistance for $\mathrm{OH}^{-}$. The slope values of the electrode materials are shown in Fig. 5e. The $\mathrm{NiMoCo}-\mathrm{LDH} / \mathrm{NF}$ catalyst possesses a smaller value than other samples, indicating a quick transmission path for $\mathrm{OH}^{-}$. As seen from Fig. 5f, the NiMoCo-LDH/NF elec- trode exhibits excellent stability.

Based on the above catalytic properties of the NiMoCoLDH/NF electrode for HER and OER, it can be directly used as an electrocatalyst for overall water splitting. Thus, a two-electrode system was constructed using NiMoCo$\mathrm{LDH} / \mathrm{NF}$ as anode and cathode, respectively. The system was measured in $1.0 \mathrm{~mol} \mathrm{~L}^{-1} \mathrm{KOH}$ at a scan rate of $5 \mathrm{mV} \mathrm{s}^{-1}$. Fig. 6 a is a schematic of overall water splitting of the NiMoCo-LDH/NF samples. In Fig. 6b, the voltage
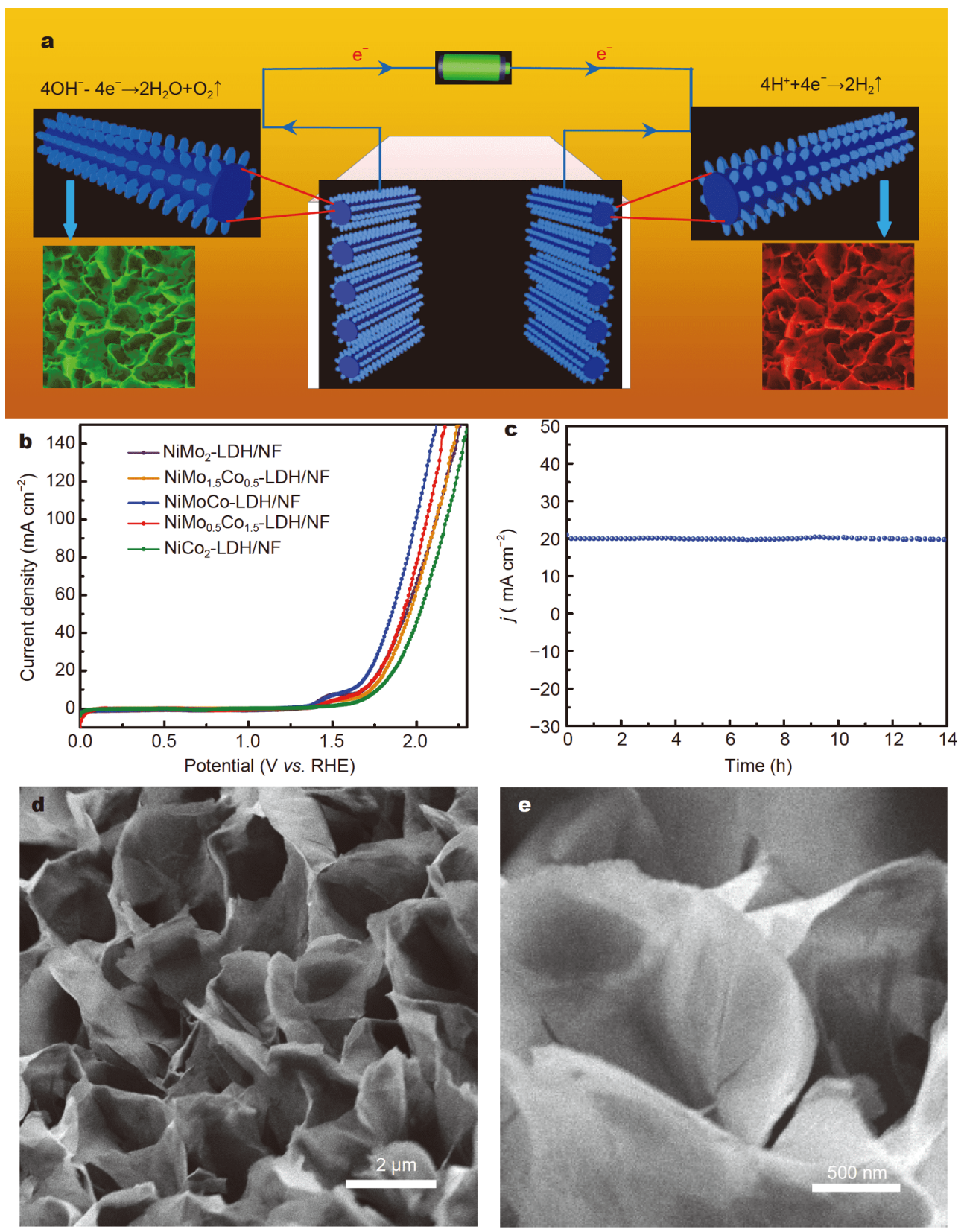

Figure 6 (a) Schematic of overall water splitting; (b) polarization curves of the as-prepared samples for overall water splitting; (c) durability of the NiMoCo-LDH/NF sample; (d) low- and (e) high-magnification SEM images of the NiMoCo-LDH/NF sample after overall water splitting. 
of the sample is $1.71 \mathrm{~V}$ at $20 \mathrm{~mA} \mathrm{~cm}^{-2}$. It indicates that this electrode possesses excellent electrocatalytic performance. Long-term durability of the sample was measured by multiple voltage tests for $14 \mathrm{~h}$. Its current densities do not significantly decrease, as shown in Fig. 6c. Meanwhile, no obvious morphology change is observed from SEM images of the sample (Fig. 6d, e), which further demonstrates the excellent stability.

The excellent overall water splitting performance of the NiMoCo-LDH/NF electrocatalyst might be from the following factors. Firstly, the nanosheet structure shows distinctive advantages with easy electrolyte diffusion and ionic transportation and offers a large surface area with sufficient contact between the electrode and electrolyte. Then, the 3D NF offers a persevering skeleton, which avoids "dead surface" and ensures easy diffusion.

The supercapacitor performances of the samples were studied using $3 \mathrm{~mol} \mathrm{~L}^{-1} \mathrm{KOH}$ solution as the electrolyte. Figs S1a, b and S2a-c show the CV curves of the electrode materials at a scan rate of $5-100 \mathrm{mV} \mathrm{s}^{-1}$. The voltage window of the as-prepared materials is $0-0.5 \mathrm{~V}$. As the scan rate increases, no obvious change in the shape is found, indicating their excellent reversibility. GCD curves of the above mentioned samples are shown in Figs S1c, d and S2d-f, respectively. With increasing current density, the discharge time of the electrode materials gradually decreases.
$\mathrm{CV}$ curves of the as-prepared samples at a scan rate of $100 \mathrm{mV} \mathrm{s}^{-1}$ are shown in Fig. 7a. The specific capacitance of the electrode is directly proportional to the curve area. The curve of NiMoCo-LDH/NF shows the largest area, indicating that it possesses the highest specific capacitance among the five electrodes. In Fig. $7 \mathrm{~b}$, it is found that NiMoCo-LDH/NF exhibits much longer discharge time than the other electrodes. In addition, the charge and discharge times of the curves are almost the same, demonstrating the reversibility of all electrode materials. As shown in Fig. $7 \mathrm{c}$, the specific capacitance of NiMoCo$\mathrm{LDH} / \mathrm{NF}$ reaches $642.1 \mathrm{C} \mathrm{g}^{-1}$ when the current density is $1 \mathrm{~A} \mathrm{~g}^{-1}$, and the capacitance retention is $85.3 \%$ at a current density of $8 \mathrm{Ag}^{-1}$. When the current density increases, the capacitance retentions of the other electrodes are less than $85.3 \%$ (77.6\% for $\mathrm{NiMo}_{2}-\mathrm{LDH} / \mathrm{NF}, 82.1 \%$ for $\mathrm{NiMo}_{1.5} \mathrm{Co}_{0.5}-\mathrm{LDH} / \mathrm{NF}, 70.3 \%$ for $\mathrm{NiMo}_{0.5} \mathrm{Co}_{1.5}-\mathrm{LDH} / \mathrm{NF}$ and $72.9 \%$ for $\mathrm{NiCo}_{2}-\mathrm{LDH} / \mathrm{NF}$ ).

EIS of the electrodes are shown in Fig. 7d. The curve of NiMoCo-LDH/NF possesses maximum slope and minimum intercept $(0.45 \Omega)$, suggesting that the diffusion of redox species in the electrolyte can be revealed from the low frequency range. The diffusion-controlled and pesudocapacitive contributions were calculated from the $\mathrm{CV}$ curves (Fig. 7e). The diffusion-controlled charges are about $75.1 \%$ of the total charge storage at a scan rate of $5 \mathrm{mV} \mathrm{s}^{-1}$, which indicates an effective diffusion charge
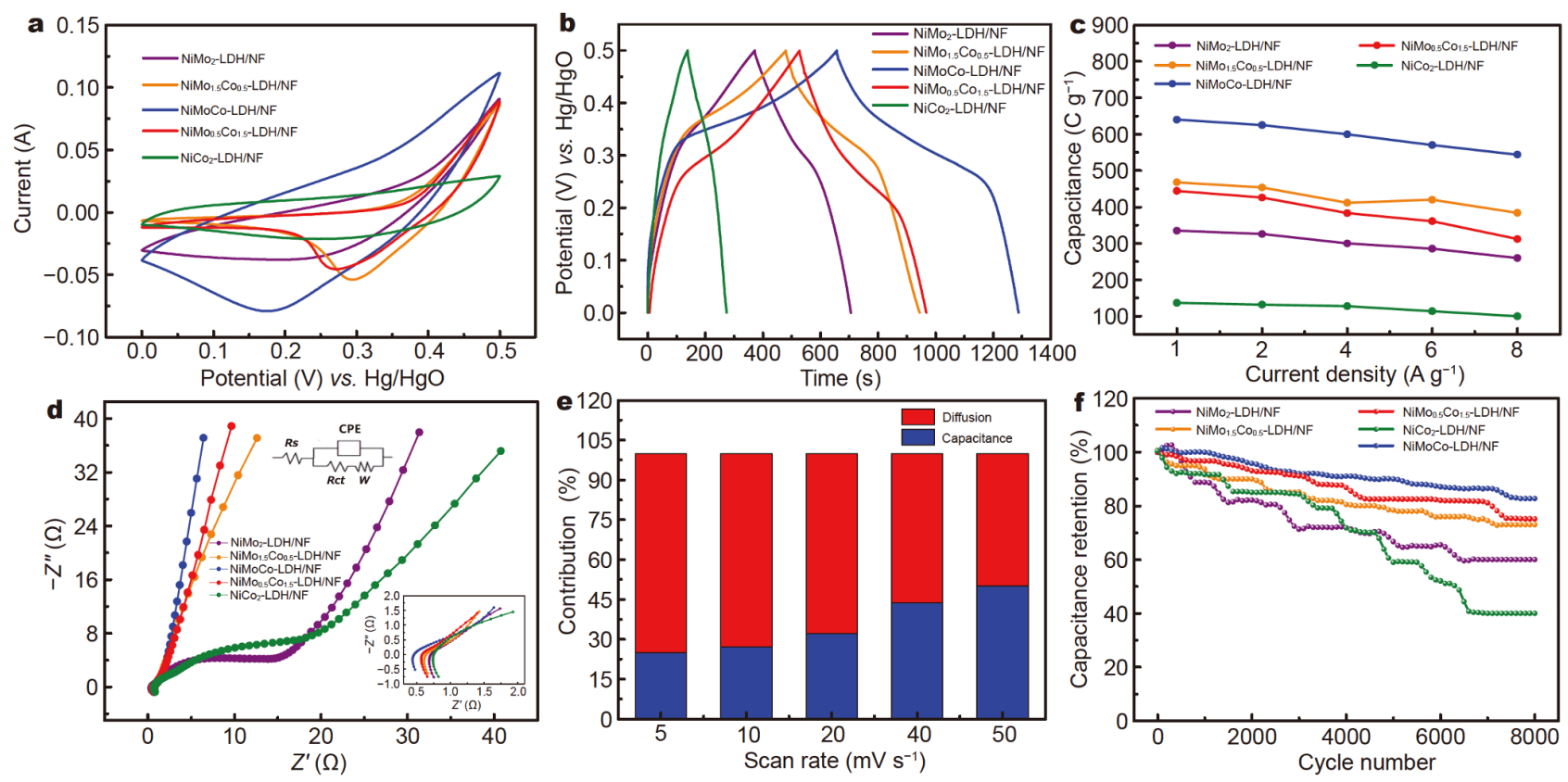

Figure 7 Electrochemical characterizations for supercapacitor performances: (a) CV and (b) GCD curves, (c) specific capacitances, (d) Nyquist plots, (e) contribution ratios between capacitances and diffusion-limited ones, (f) cycling performances. 

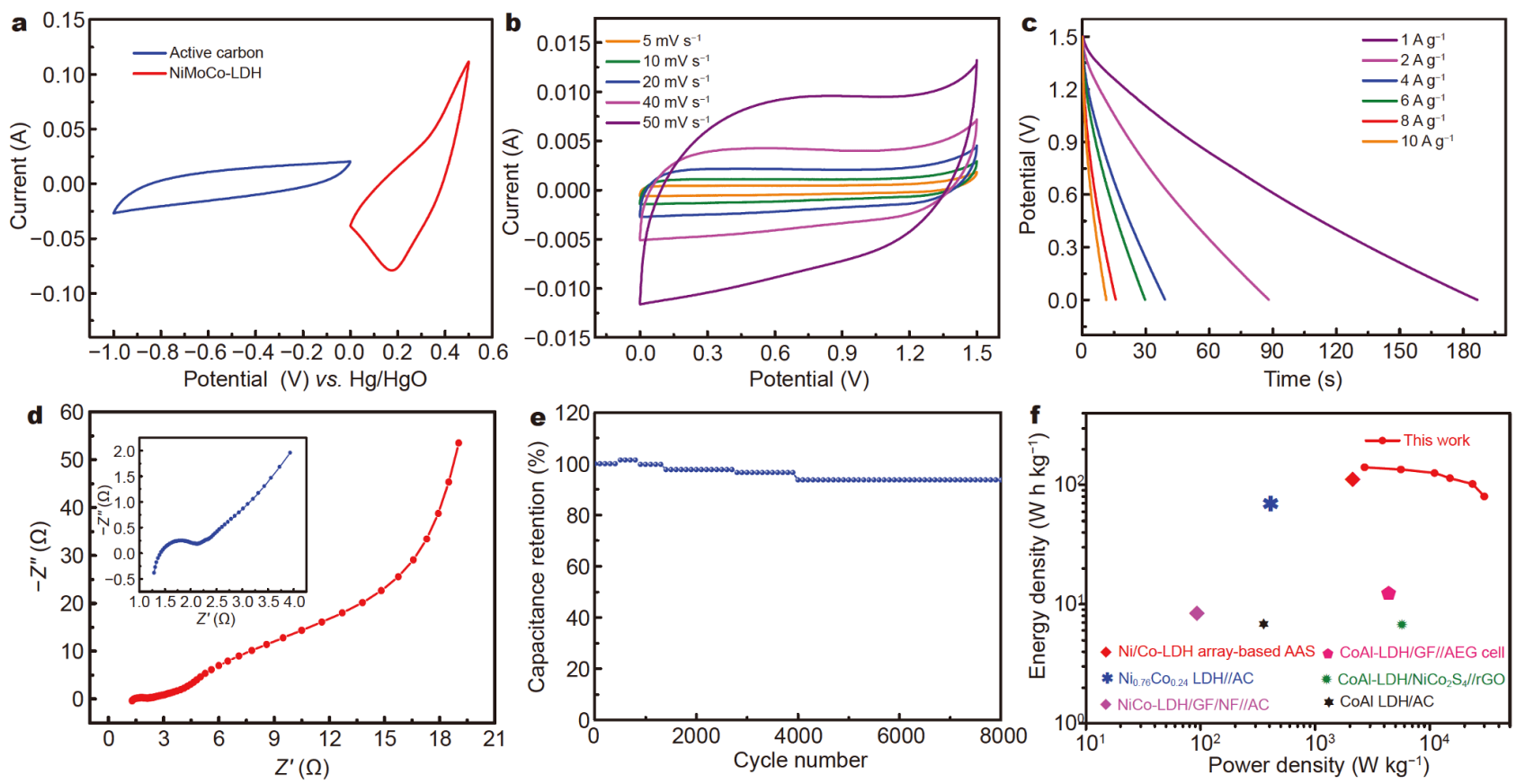

Figure 8 Electrochemical characterizations of the NiMoCo-LDH/NF//AC ASC. (a) CV curves of AC and NiMoCo-LDH/NF, (b) CV curves at different scan rates, (c) GCD curves, (d) Nyquist plots, (e) cycling performance, (f) Ragone plots.

storage ability of the NiMoCo-LDH/NF electrode. The cycling performances (Fig. 7f) of the as-prepared electrodes were obtained by 8000 charge-discharge cycling at a current density of $10 \mathrm{~A} \mathrm{~g}^{-1}$. The capacitance retention of the NiMoCo- $\mathrm{LDH} / \mathrm{NF}$ electrode is $82.7 \%$, much higher than those of the other electrodes. In Fig. S3, the Coulombic efficiency of the electrode materials are close to $100 \%$, indicating that the charging and discharging times of the samples are similar during the cycle.

In order to further study the practical application of the electrode material, an ASC was assembled by using $\mathrm{Ni}$ MoCo-LDH/NF as the anode and $\mathrm{AC}$ as the cathode. $\mathrm{CV}$ curves of the NiMoCo-LDH/NF sample and AC electrode are shown in Fig. 8a, within the potential windows of 0 0.5 and $-1.0-0 \mathrm{~V}$, respectively. Therefore, the theoretical voltage window of the assembled supercapacitor can reach $1.5 \mathrm{~V}$. Fig. $8 \mathrm{~b}$ shows the $\mathrm{CV}$ curves of the device at scan rates from 5 to $50 \mathrm{mV} \mathrm{s}^{-1}$. The $\mathrm{CV}$ curves keep similar shapes when the current density increases by 5 times. Discharge curves from 0 to $1.52 \mathrm{~V}$ were also studied at various current densities (Fig. 8c). The specific capacitance reaches $119 \mathrm{C} \mathrm{g}^{-1}$ at a current density of $1 \mathrm{~A} \mathrm{~g}^{-1}$. In Fig. 8d, it is found that the NiMoCo-LDH/ $\mathrm{NF} / / \mathrm{AC}$ ASC shows a low bulk resistance, and the internal resistance is $1.43 \Omega$. In Fig. 8e, the capacitance retention of the device is $93 \%$ after 8000 cycles. According to the discharge curves, the power densities and energy densities of the NiMoCo-LDH/NF//AC ASC are shown in Fig. 8f. A maximum energy density of $141 \mathrm{~W} \mathrm{~h} \mathrm{~kg}^{-1}$ at a power density of $2695 \mathrm{~W} \mathrm{~kg}^{-1}$ is obtained, which are superior to some previous reports [45-50].

\section{CONCLUSION}

In summary, we have synthesized a NiMoCo-LDH/NF elecrocatalyst on NF via a facile hydrothermal method. The as-obtained sample shows outstanding performances for HER and OER with a lower overpotential. As bifunctional electrocatalyst for overall water splitting, it shows a low voltage. The remarkable electrochemical performance can be attributed to its unique structure. As the electrode for capacitor, it delivers high specific capacitance and excellent cyclic performance. The asassembled NiMoCo-LDH/NF//AC ASC exhibits high energy density at a power density of $2695 \mathrm{~W} \mathrm{~kg}^{-1}$ and $93 \%$ of its capacitance retention after 8000 cycles.

Received 10 May 2020; accepted 26 June 2020; published online 11 September 2020

1 Yan D, Li Y, Huo J, et al. Defect chemistry of nonprecious-metal electrocatalysts for oxygen reactions. Adv Mater, 2017, 29: 1606459

2 Zhao D, Liu H, Wu X. Bi-interface induced multi-active $\mathrm{MCo}_{2} \mathrm{O}_{4} @$ $\mathrm{MCo}_{2} \mathrm{~S}_{4} @ \mathrm{PPy}(\mathrm{M}=\mathrm{Ni}, \mathrm{Zn})$ sandwich structure for energy storage 
and electrocatalysis. Nano Energy, 2019, 57: 363-370

3 Liu C, Wu X, Wang B. Performance modulation of energy storage devices: a case of Ni-Co-S electrode materials. Chem Eng J, 2020, 392: 123651

4 Huang Y, Li M, Yang W, et al. 3D ordered mesoporous cobalt ferrite phosphides for overall water splitting. Sci China Mater, 2020, 63: 240-248

5 Liu $\mathrm{H}$, Zhao $\mathrm{D}, \mathrm{Hu}$, et al. Design strategies toward achieving high-performance $\mathrm{CoMoO}_{4} @ \mathrm{Co}_{1.62} \mathrm{Mo}_{6} \mathrm{~S}_{8}$ electrode materials. Mater Today Phys, 2020, 13: 100197

$6 \mathrm{Ni} \mathrm{B}, \mathrm{Wu} \mathrm{L}$, Chen R, et al. Fe/Co-based nanoparticles encapsulated in heteroatom-doped carbon electrocatalysts for oxygen reduction reaction. Sci China Mater, 2019, 62: 1626-1641

7 Zhao D, Dai M, Zhao Y, et al. Improving electrocatalytic activities of $\mathrm{FeCo}_{2} \mathrm{O}_{4} @ \mathrm{FeCo}_{2} \mathrm{~S}_{4} @ P P y$ electrodes by surface/interface regulation. Nano Energy, 2020, 72: 104715

8 Yao M, Wang B, Wang N, et al. Self-supported composite of (Ni, $\mathrm{Co})_{3} \mathrm{C}$ mesoporous nanosheets/N-doped carbon as a flexible electrocatalyst for $\mathrm{pH}$-universal hydrogen evolution. ACS Sustain Chem Eng, 2020, 8: 5287-5295

9 Morales-Guio CG, Stern LA, Hu X. Nanostructured hydrotreating catalysts for electrochemical hydrogen evolution. Chem Soc Rev, 2014, 43: 6555-6569

10 Dai M, Zhao D, Liu $\mathrm{H}$, et al. Nanostructure and doping engineering of $\mathrm{ZnCoP}$ for high performance electrolysis of water. Mater Today Energy, 2020, 16: 100412

11 Liu H, Zhao D, Liu Y, et al. Boosting energy storage and electrocatalytic performances by synergizing $\mathrm{CoMoO}_{4} @ \mathrm{MoZn}_{22}$ coreshell structures. Chem Eng J, 2019, 373: 485-492

12 Yuan CZ, Jiang YF, Wang Z, et al. Cobalt phosphate nanoparticles decorated with nitrogen-doped carbon layers as highly active and stable electrocatalysts for the oxygen evolution reaction. J Mater Chem A, 2016, 4: 8155-8160

13 Zhao D, Dai M, Liu H, et al. Constructing high performance hybrid battery and electrocatalyst by heterostructured $\mathrm{NiCo}_{2} \mathrm{O}_{4} @$ NiWS nanosheets. Cryst Growth Des, 2019, 19: 1921-1929

14 Zhou W, Jia J, Lu J, et al. Recent developments of carbon-based electrocatalysts for hydrogen evolution reaction. Nano Energy, 2016, 28: 29-43

15 Pi Y, Zhang N, Guo S, et al. Ultrathin laminar Ir superstructure as highly efficient oxygen evolution electrocatalyst in broad $\mathrm{pH}$ range. Nano Lett, 2016, 16: 4424-4430

16 Yao M, Hu H, Wang N, et al. Quaternary (Fe/Ni)(P/S) mesoporous nanorods templated on stainless steel mesh lead to stable oxygen evolution reaction for over two months. J Colloid Interface Sci, 2020, 561: 576-584

17 Zhao D, Dai M, Liu H, et al. Sulfur-induced interface engineering of hybrid $\mathrm{NiCo}_{2} \mathrm{O}_{4} @ \mathrm{NiMo}_{2} \mathrm{~S}_{4}$ structure for overall water splitting and flexible hybrid energy storage. Adv Mater Interfaces, 2019, 6: 1901308

18 Dinh KN, Zheng P, Dai Z, et al. Ultrathin porous NiFeV ternary layer hydroxide nanosheets as a highly efficient bifunctional electrocatalyst for overall water splitting. Small, 2018, 14: 1703257

19 Xiao K, Zhou L, Shao M, et al. Fabrication of $(\mathrm{Ni}, \mathrm{Co})_{0.85} \mathrm{Se}$ nanosheet arrays derived from layered double hydroxides toward largely enhanced overall water splitting. J Mater Chem A, 2018, 6: 7585-7591

20 Yang Y, Zhang W, Xiao Y, et al. $\mathrm{CoNiSe}_{2}$ heteronanorods decorated with layered-double-hydroxides for efficient hydrogen evolution. Appl Catal B-Environ, 2019, 242: 132-139
21 Chen W, Fang J, Zhang Y, et al. Morphological and structure dual modulation of cobalt-based layer double hydroxides by Ni doping and 2-methylimidazole inducting as bifunctional electrocatalysts for overall water splitting. J Power Sources, 2018, 400: 172-182

22 Shao M, Ning F, Wei M, et al. Hierarchical nanowire arrays based on $\mathrm{ZnO}$ core-layered double hydroxide shell for largely enhanced photoelectrochemical water splitting. Adv Funct Mater, 2014, 24 : 580-586

23 Yang R, Zhou Y, Xing Y, et al. Synergistic coupling of CoFe-LDH arrays with $\mathrm{NiFe}-\mathrm{LDH}$ nanosheet for highly efficient overall water splitting in alkaline media. Appl Catal B-Environ, 2019, 253: 131139

24 Jiang J, Zhang A, Li L, et al. Nickel-cobalt layered double hydroxide nanosheets as high-performance electrocatalyst for oxygen evolution reaction. J Power Sources, 2015, 278: 445-451

25 Tang D, Han Y, Ji W, et al. A high-performance reduced graphene oxide/ZnCo layered double hydroxide electrocatalyst for efficient water oxidation. Dalton Trans, 2014, 43: 15119-15125

26 Yao M, Hu H, Sun B, et al. Self-supportive mesoporous Ni/Co/Fe phosphosulfide nanorods derived from novel hydrothermal electrodeposition as a highly efficient electrocatalyst for overall water splitting. Small, 2019, 15: 1905201

27 Chanda D, Basu S. Electrochemical synthesis of Li-doped NiFeCo oxides for efficient catalysis of the oxygen evolution reaction in an alkaline environment. Int J Hydrogen Energy, 2018, 43: 2199922011

28 Xie Y, Dong F, Heinbuch S, et al. Oxidation reactions on neutral cobalt oxideclusters: Experimental and theoretical studies. Phys Chem Chem Phys, 2010, 12: 947-959

29 Cheng D, Yang Y, Xie J, et al. Hierarchical $\mathrm{NiCo}_{2} \mathrm{O}_{4} @ \mathrm{NiMoO}_{4}$ core-shell hybrid nanowire/nanosheet arrays for high-performance pseudocapacitors. J Mater Chem A, 2015, 3: 14348-14357

30 Yisup N, Cao Y, Feng WL, et al. Catalytic oxidation of methane over novel Ce-Ni-O mixed oxide catalysts prepared by oxalate gelcoprecipitation. Catal Lett, 2005, 99: 207-213

$31 \mathrm{Wu} \mathrm{X}$, Han Z, Zheng X, et al. Core-shell structured $\mathrm{Co}_{3} \mathrm{O}_{4} @$ $\mathrm{NiCo}_{2} \mathrm{O}_{4}$ electrodes grown on flexible carbon fibers with superior electrochemical properties. Nano Energy, 2017, 31: 410-417

32 Zhao Y, He J, Dai M, et al. Emerging CoMn-LDH@ $\mathrm{MnO}_{2}$ electrode materials assembled using nanosheets for flexible and foldable energy storage devices. J Energy Chem, 2020, 45: 67-73

$33 \mathrm{Hu} \mathrm{P}$, Zhao D, Liu $\mathrm{H}$, et al. Engineering PPy decorated $\mathrm{MnCo}_{2} \mathrm{O}_{4}$ urchins for quasi-solid-state hybrid capacitors. CrystEngComm, 2019, 21: 1600-1606

34 He X, Li R, Liu J, et al. Hierarchical $\mathrm{FeCo}_{2} \mathrm{O}_{4} @ \mathrm{NiCo}$ layered double hydroxide core/shell nanowires for high performance flexible allsolid-state asymmetric supercapacitors. Chem Eng J, 2018, 334: 1573-1583

35 Yang J, Yu C, Fan X, et al. 3D architecture materials made of $\mathrm{NiCoAl-LDH}$ nanoplates coupled with $\mathrm{NiCo}$-carbonate hydroxide nanowires grown on flexible graphite paper for asymmetric supercapacitors. Adv Energy Mater, 2014, 4: 1400761

36 Zhou JJ, Li Q, Chen C, et al. $\mathrm{Co}_{3} \mathrm{O}_{4} @ \mathrm{CoNi}-\mathrm{LDH}$ core/shell nanosheet arrays for high-performance battery-type supercapacitors. Chem Eng J, 2018, 350: 551-558

37 Zhao X, Liu X, Huang B, et al. Hydroxyl group modification improves the electrocatalytic ORR and OER activity of graphene supported single and bi-metal atomic catalysts ( $\mathrm{Ni}, \mathrm{Co}$, and $\mathrm{Fe}$ ). J Mater Chem A, 2019, 7: 24583-24593

38 Fang Z, Peng L, Qian Y, et al. Dual tuning of Ni-Co-A (A = P, Se, 
O) nanosheets by anion substitution and holey engineering for efficient hydrogen evolution. J Am Chem Soc, 2018, 140: 52415247

39 Liu S, Ni D, Li HF, et al. Effect of cation substitution on the pseudocapacitive performance of spinel cobaltite $\mathrm{MCo}_{2} \mathrm{O}_{4}(\mathrm{M}=$ $\mathrm{Mn}, \mathrm{Ni}, \mathrm{Cu}$, and Co). J Mater Chem A, 2018, 6: 10674-10685

40 Tong YL, Xing L, Dai MZ, et al. Hybrid $\mathrm{Co}_{3} \mathrm{O}_{4} @ \mathrm{Co}_{9} \mathrm{~S}_{8}$ electrocatalysts for oxygen evolution reaction. Front Mater, 2019, 6: 233

41 Fang L, Wang F, Zhai T, et al. Hierarchical $\mathrm{CoMoO}_{4}$ nanoneedle electrodes for advanced supercapacitors and electrocatalytic oxygen evolution. Electrochim Acta, 2018, 259: 552-558

42 Gong Y, Yang Z, Lin Y, et al. Hierarchical heterostructure $\mathrm{NiCo}_{2} \mathrm{O}_{4} @ \mathrm{CoMoO}_{4} / \mathrm{NF}$ as an efficient bifunctional electrocatalyst for overall water splitting. J Mater Chem A, 2018, 6: 16950-16958

43 Wang X, Kolen'ko YV, Bao XQ, et al. One-step synthesis of selfsupported nickel phosphide nanosheet array cathodes for efficient electrocatalytic hydrogen generation. Angew Chem Int Ed, 2015, 54: 8188-8192

44 Zhuang Z, Sheng W, Yan Y. Synthesis of monodispere $\mathrm{Au} @ \mathrm{Co}_{3} \mathrm{O}_{4}$ core-shell nanocrystals and their enhanced catalytic activity for oxygen evolution reaction. Adv Mater, 2014, 26: 3950-3955

45 Li T, Li R, Luo H. Facile in situ growth of Ni/Co-LDH arrays by hypothermal chemical coprecipitation for all-solid-state asymmetric supercapacitors. J Mater Chem A, 2016, 4: 18922-18930

46 Masikhwa TM, Madito MJ, Momodu DY, et al. High performance asymmetric supercapacitor based on CoAl-LDH/GF and activated carbon from expanded graphite. RSC Adv, 2016, 6: 46723-46732

47 Wang X, Li X, Du X, et al. Controllable synthesis of NiCo LDH nanosheets for fabrication of high-performance supercapacitor electrodes. Electroanalysis, 2017, 29: 1286-1293

48 Zhang X, Wang S, Xu L, et al. Controllable synthesis of crosslinked CoAl-LDH/ $/ \mathrm{NiCo}_{2} \mathrm{~S}_{4}$ sheets for high performance asymmetric supercapacitors. Ceramics Int, 2017, 43: 14168-14175

49 Liu L, Guan T, Fang L, et al. Self-supported 3D NiCo-LDH/Gr composite nanosheets array electrode for high-performance supercapacitor. J Alloys Compd, 2018, 763: 926-934

50 Jing C, Liu X, Yao H, et al. Phase and morphology evolution of CoAl LDH nanosheets towards advanced supercapacitor applications. CrystEngComm, 2019, 21: 4934-4942

Acknowledgements This work was supported by Guangxi Key Laboratory of Information Materials, Guilin University of Electronic Technology (191010-K), the Education Department Funding of Liaoning Province (LJGD2019001), and the Funding of Science and Technology Bureau, Shenyang City (RC190138).

Author contributions Liu $\mathrm{H}$ and Zhao D did the experiments and wrote the original draft. Liu $Y$ contributed to visualization and investigation. Tong $\mathrm{Y}$ helped with software and validation. $\mathrm{Wu} \mathrm{X}$ supervised, reviewed and edited the manuscript. Shen G supervised the study and gave some advice.

Conflict of interest The authors declare that they have no conflict of interest.

Supplementary information online version of the paper.

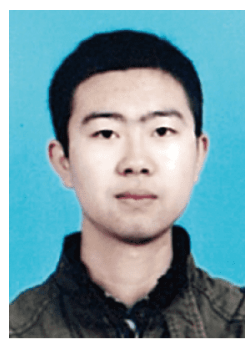

Hengqi Liu received his BS degree in materials science and engineering from Liaoning University of Technology, China, in 2017. One year later, he joined Prof. Xiang Wu's group at Shenyang University of Technology, China, for pursuing his MSc degree in materials engineering. His research interest focuses on electrochemical capacitor and electrocatalysts.

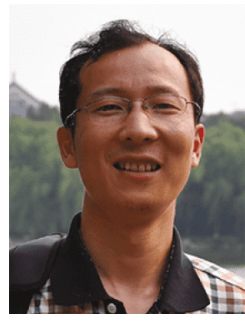

Xiang Wu received his $\mathrm{PhD}$ degree in materials science and engineering from Harbin Institute of Technology in 2008. After that he joined Harbin Normal University and stayed there until September 2016. He ever worked as a visiting scientist in the National Institute for Materials Science (NIMS), Japan, and Taiwan University. He is now a full professor of materials science at Shenyang University of Technology, China. His research interests focus on the syntheses and characterization of semiconductor nanomaterials and their applications in environment and energy fields.

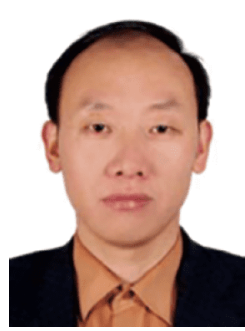

Guozhen Shen received his BSc degree (1999) in chemistry from Anhui Normal University and PhD degree (2003) in chemistry from the University of Science and Technology of China. He joined the Institute of Semiconductors, Chinese Academy of Sciences as a professor in 2013. His current research focuses on flexible electronics and printable electronics, including transistors, photodetectors, sensors and flexible energy storage and conversion devices.

\section{基于NiMoCo层状双金属氢氧化物的电催化剂和 超级电容器电极}

刘恒岐 ${ }^{1}$, 赵德鹏 ${ }^{1}$, 刘颖 ${ }^{1}$, 佟永丽 ${ }^{1}$, 武祥 ${ }^{*}$, 沈国 震 $^{2^{*}}$

摘要 本文通过调控 $\mathrm{Ni}, \mathrm{Mo}, \mathrm{Co}$ 三种元素的摩尔比得到一系列高效 双功能电催化剂. 其中, $\mathrm{Co}$ 元素特定的氧吸附位点 $\left(\mathrm{Co}^{2+}-\mathrm{O}-\mathrm{Co}^{3+}\right)$ 可 有效提高催化剂的活性. Mo元素在温和反应条件下具有较好的氧 化还原能力. $\mathrm{Ni}$ 是另一种高活性过渡金属. 与其他材料结合可有效 增强催化剂的氧化还原活性和储氧能力. 所制备的NiMoCo 层状双 金属氢氧化物( $\mathrm{NiMoCo}-\mathrm{LDH}$ )催化剂在 $10 \mathrm{~m} \mathrm{~A} \mathrm{~cm}^{-2}$ 时析氢反应 (HER) 过电势为 $123 \mathrm{mV}, 20 \mathrm{~mA} \mathrm{~cm}^{-2}$ 时析氧反应( OER)过电势为 $251 \mathrm{mV}$. 该材料还表现出优异的全解水性能, 为构筑过渡金属氢氧 化物电催化剂提供了崭新思路. 同时, 所制备的电极材料用作超级 电容器正极时也表现出优异的性能. 在 $1 \mathrm{~A} \mathrm{~g}^{-1}$ 的电流密度下, $\mathrm{NiMoCo}-\mathrm{LDH}$ 电极拥有 $642.1 \mathrm{C} \mathrm{g}^{-1}$ 的比容量. 组装的 NiMoCo$\mathrm{LDH} / / \mathrm{AC}$ 非对称超级电容器在功率密度为 $2695 \mathrm{~W} \mathrm{~kg}^{-1}$ 时能量密度 为 $141 \mathrm{~W} \mathrm{~h} \mathrm{~kg}^{-1}$, 经过 8000 次充放电后仍保持初始容量的 $93 \%$. 